\title{
Outbreak of Salmonella Enteritidis phage type 13a infection in Sweden linked to imported dried-vegetable spice mixes, December 2014 to July 2015
}

C Jernberg (cecilia.jernberg@folkhalsomyndigheten.se) ${ }^{1}$, M Hjertqvist $^{1}$, C Sundborger ${ }^{1}$, E Castro $^{1}$, M Löfdahl $^{1}$, A Pääjärvi $^{1}$, L Sundqvist ${ }^{1}$, E Löf ${ }^{1}$

1. Public Health Agency of Sweden, Solna, Sweden

Citation style for this article:

Jernberg C, Hjertqvist M, Sundborger C, Castro E, Löfdahl M, Pääjärvi A, Sundqvist L, Löf E. Outbreak of Salmonella Enteritidis phage type $13 a$ infection in Sweden linked to imported dried-vegetable spice mixes, December 2014 to July 2015. Euro Surveill. 2015;20(30):pii=21194. Available online: http://www.eurosurveillance. org/ViewArticle. aspx?Articleld $=21194$

From 24 December to 24 July 2015, 174 cases were reported in a nationwide salmonellosis outbreak in Sweden: 108 cases were connected to a single restaurant. A spice mix, containing dried vegetables from the restaurant tested positive for the outbreak strain. Additional spice mixes with similar content from different suppliers also tested positive. The outbreak investigation suggests there could be a risk of contaminated products being also on the market in other countries.

At the end of March 2015, 17 cases of Salmonella Enteritidis phage type (PT) 13 a had been reported to SmiNet, the national surveillance system, from four counties in Sweden. The first case included in the outbreak was reported with onset of symptoms on 24 December 2014. By 24 July 2015, a total of 174 cases had been reported connected to the outbreak, making it one of the largest salmonellosis outbreaks in Sweden. The median age of the cases was 44 years (range: 1-93), 83 were female and 91 male, suggesting a food vehicle that could be consumed by a broad range of the population. The outbreak is still ongoing.

\section{Epidemiological and environmental investigation}

An outbreak team was formed at the Public Health Agency of Sweden at the end of March 2015. The characteristics of the first 17 cases in terms of age and sex did not differ from the distribution in the general population. The local county medical offices conducted standardised interviews with the cases using a questionnaire. The interviews were conducted either by telephone, face-to-face or the questionnaire was filled in by the case. No specific food items stood out in the responses. However, in one of the counties, four of nine cases had eaten at the same sausage food stand and in another county, three of five cases had eaten at the same lunch restaurant. In mid-April, the Public Health Agency of Sweden initiated regular telephone conferences with all the relevant local authorities. The teleconferences were held on a weekly basis till the end of June to liaise with all relevant actors at national and local level and to keep everyone updated. In July, the teleconferences were held more often, due to the development in Kalmar county (see below).

The initial investigations, summed up at the first teleconference on 17 April, suggested that the vehicle of infection was most likely a food item with a long shelf life, e.g. something frozen, nuts or spices, given that the first case had been reported in December. By the end of May, the number of cases had risen to 48 (Figure) and were distributed over 14 counties. When interviewing the cases up to this time point, use of specific spice mixes containing dried vegetables, buying food from specialised food stores, consumption of chicken stood out as over-represented among the cases, but without statistical significance. Various food items were analysed for Salmonella spp., including two different brands of spice mixes containing dried vegetables. Up to the end of June, all tested negative for Salmonella spp.

At the beginning of June (week 23), Kalmar county reported a case who had fallen ill after eating at a restaurant that served many of their dishes on wooden boards. Cases continued to be reported and at the end of the following week (week 24), a total of six cases of salmonellosis had been reported from that same county. Interviews showed that all the six cases had eaten at the same restaurant in the county within the incubation period for symptom onset. As they all shared the outbreak strain, they could be connected to the S. Enteritidis PT 13 a outbreak. The restaurant had served many guests, around 200, during the Swedish 
midsummer holiday (19-20 June), some of whom were from Denmark, Norway and Germany. Local authorities reported that the majority of the cases at the restaurant had eaten pork tenderloin, served on a wooden board together with mashed potatoes. The pork tenderloin was one of the first main suspected contaminated food sources at the restaurant outbreak; however, analyses for Salmonella spp. were negative.

A municipal environment and health team collected additional food items, serving utensils and other kitchen utensils for testing from the restaurant. On 9 July, the laboratory at the National Veterinary Institute (SVA) in Uppsala, detected a Salmonella isolate in an unopened package of a spice mix collected from the restaurant (Brand $A$ ) originating from Serbia, containing dried vegetables, e.g. onions, carrots and parsnips. This spice mix had been used in many of the dishes. In addition, a pastry bag used for piping mashed potatoes servings was found positive for the outbreak strain. The mashed potatoes had been seasoned with the spice mix (Brand A). In total, 108 cases were connected to the restaurant, including staff members. Local authorities reported that many of the cases had severe symptoms, including bacteraemia, and were hospitalised. The exact numbers hospitalised is currently not yet verified.

\section{Microbiological investigation}

In Sweden, S. Enteritidis is the second most common serotype comprising $19 \%$ (97/501) of the domestic cases reported in 2014 [1]. The majority of isolates from domestic cases (>90\%) are sent to the Public Health Agency of Sweden in Solna for subtyping for outbreak detection and surveillance purposes. Each year, two to five cases with PT 13a are reported. In 2014, four of the domestic S. Enteritidis cases were PT 13a [1].

Phage typing has been the gold standard for subtyping of S. Enteritidis [2]; however, multiple-locus variablenumber of tandem-repeats analysis (MLVA) [3] was recently set up at the Agency, enabling further subtyping of isolates. Whole genome sequencing as a firstline tool for typing is under development at the Agency. All three methods were used in the current outbreak.

As at 24 July, 174 cases in the outbreak had been laboratory confirmed with salmonellosis. Of these, $123 \mathrm{had}$ been further subtyped as S. Enteritidis PT 13a; the additional 51 salmonellosis cases were epidemiologically linked to the outbreak. In addition, 102 human isolates and all six environmental isolates had been further subtyped by MLVA. Before the onset of the outbreak in Kalmar county, three profiles had been identified in the national outbreak. According to the nomenclature SENT7-SENT5-SENT6-SENT4-SE3 [3], their profiles were 2-10-7-5-2, 2-12-8-5-2 and 2-11-6-5-2. Cases with the same MLVA profile were at that time point more or less evenly distributed both in time and place, i.e. there was no clustering of a specific MLVA profile in one county or on one specific occasion limited in time. In the Kalmar county restaurant outbreak the profile 2-11-6-5-2 was the only one identified.

A subset of human isolates $(n=12)$, four from each MLVA profile, was analysed by whole genome sequencing using the Ion Torrent platform at the Agency. Within each MLVA profile, the isolates were identical or differed by one single nucleotide polymorphism (SNP). Between the three MLVA profiles, the isolates differed by about 40-50 SNPs.

All three MLVA profiles were regarded as being part of the same outbreak because the particular PT (13a) is normally only seen up to five times a year in Sweden. Moreover, the scenario that three parallel outbreaks (parallel in terms of time and place) of PT 13a infection were taking place seemed unlikely. A plausible scenario was that the source of the bacteria was contaminated with multiple $S$. Enteritidis subtypes. All isolates from the cases connected to the outbreak in Kalmar county that had been typed as at 24 July $(n=43)$ had the same MLVA profile (2-11-6-5-2), as did isolates from the Brand A spice mix $(n=3)$ and the pastry bag from the restaurant $(n=1)$.

\section{International aspects}

Sweden launched an 'urgent inquiry' in the Epidemic Intelligence Information System (EPIS) [4], a webbased communication platform run by the European Centre for Disease Prevention and Control (ECDC), on 2 April 2015. No other country has to date reported an increase of this specific subtype of $S$. Enteritidis. However, many European Union Member States only subtype $S$. Enteritidis in outbreak situations or cluster investigations and in addition, phage typing or MLVA is not performed in all EU countries. Thus, a relatively minor increase in number of cases with this $S$. Enteritidis PT could go unnoticed.

A Rapid Alert System for Food and Feed (RASFF) [5] alert (reference 2015.0825) was issued by Austria on 26 June, in which it was reported that a Salmonella spp. had been detected in a spice mix/seasoning Brand $B$ from a manufacturer in Croatia, with a similar content of dried vegetables as Brand $A$. Batches of this product, which had been distributed to Austria, Germany and Slovakia, were voluntarily recalled from the market by the manufacturer (announced in a press release by the company on 1 July). The specific batch of Brand B from which Salmonella spp. had been detected had not been distributed to Sweden. The serotype, however, was S. Oranienburg (not S. Enteritidis PT 13a), according to the Austrian Salmonella Reference Centre (Christian Kornschober, personal communication, 27 July 2015).

The Swedish National Food Agency issued a RASFF notification for information on 9 July (reference 2015.0873), after the Brand A spice mix had been found positive for Salmonella Enteritidis in the outbreak in Kalmar county. 
Number of salmonellosis cases by week number of symptom onset connected to the Salmonella Enteritidis phage type 13a outbreak, Sweden, 24 December 2014-24 July 2015 $(\mathrm{n}=174)$

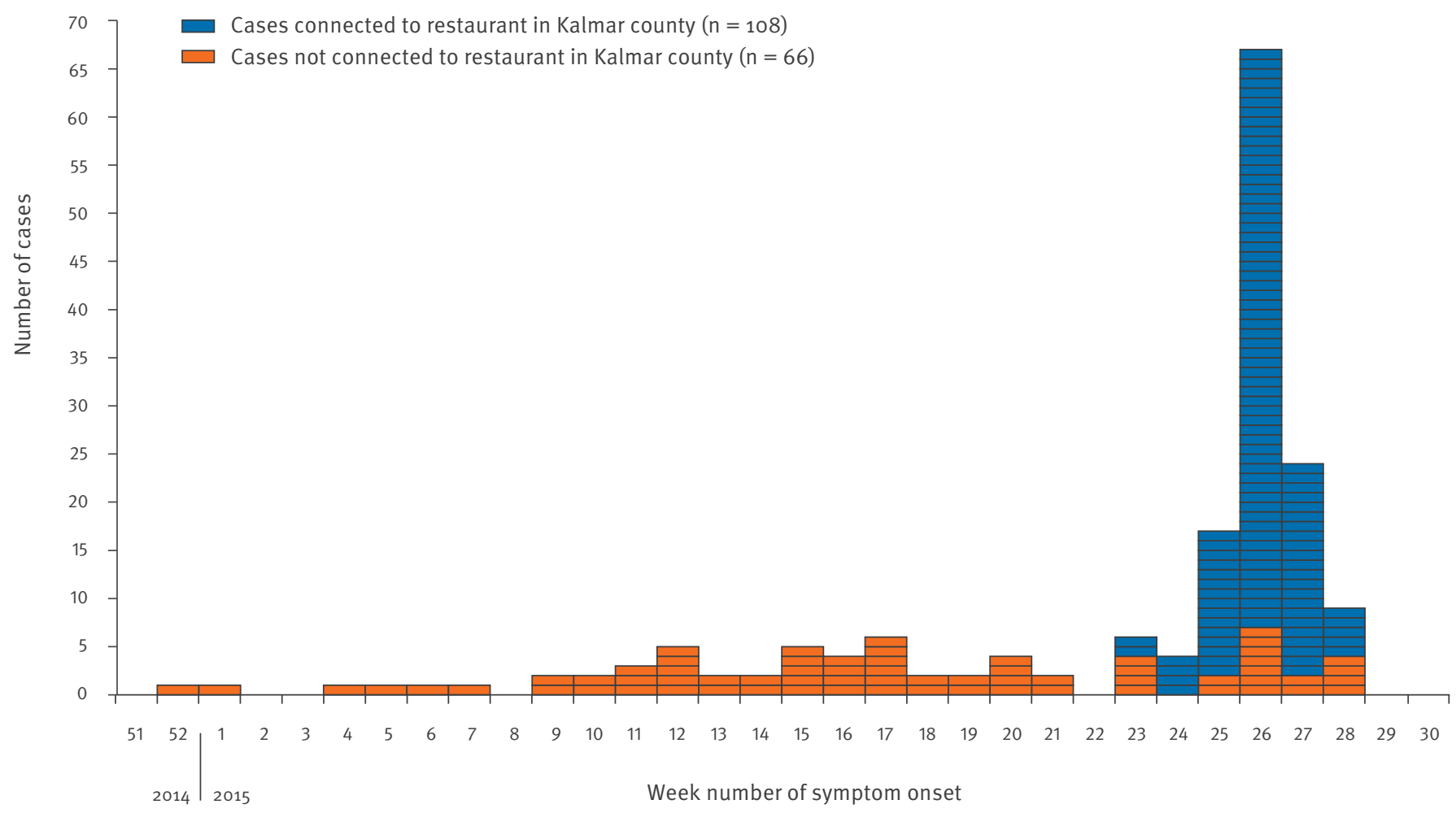

a Week 522014 to week 302015.

Whole genome sequencing data were shared with Public Health England, United Kingdom, which had during 2009 to 2014 reported the largest number (48\%) of S. Enteritidis PT 13 a to the European Surveillance System (TESSy) [6], the ECDC system for reporting data. In addition, comparison with an S. Enteritidis PT 13a isolate from Luxemburg from 2014, sharing one of the MLVA profiles, was compared using whole genome sequencing data. No clustering of the isolates indicating relationship with the Swedish outbreak could be seen, as assessed by whole genome sequencing.

\section{Testing of food items}

In addition to the $S$. Enteritidis PT 13a-positive Brand A spice mix from an unopened package from the restaurant, two more samples (opened packages) of Brand $A$, from two other counties in Sweden tested positive for PT 13 a in July. These two additional positive samples of Brand A had the same MLVA profile as the isolate from the spice mix from the restaurant in Kalmar county (2-11-6-5-2). Two Brand C spice mix samples, manufactured in Bosnia and Herzegovina and Serbia, which came from opened packages from two different households in Sweden, had two different profiles: $2-10-7-5-2$, which is one of the profiles seen in cases in the ongoing outbreak, and $2-10-8-8-2$, which is a profile that has not been identified in cases in this outbreak. When an opened package is found positive for Salmonella spp., this could mean that the spice mix had been contaminated after opening. The manufacturer of Brand $C$ voluntarily recalled the product on 6 July as a precaution, after they were informed about a possible link of the product to the outbreak.

During the analysis of the food items, and specifically the spice mixes, it was observed that a more sensitive method than the commonly used Nordisk Metodikkommitté för Livsmedel (NMKL) number 71 method, corresponding to International Organization for Standardization (ISO) 6579:2002/Corr 1:4 [7], could be needed. Additional dilution steps and number of replicates were often necessary in order to detect and isolate Salmonella spp., indicating very low concentration of the pathogen in the spices.

\section{Background}

Salmonella spp. can survive for an extended period of time (exceeding one year) in dried products such as spices, due to high tolerance to desiccation stress [8]. Contamination of spices with Salmonella spp. can be from a wide variety of sources, such as soil, water, rodents, birds and insects [8]. The United States (US) Food and Drug Administration (FDA) have shown a wide diversity of Salmonella spp. serotypes in spices imported to the US, which may well be a reflection of the wide range of the sources of contamination [8]. Several outbreaks of Salmonella spp. infection 
associated with spices in Europe identified many different serotypes within the same outbreak $[9,10]$.

Spices and herbs contaminated with Salmonella spp. have been associated with a variety of food-borne outbreaks in Europe and North America [11]. The largest spice-associated salmonellosis outbreak occurred in 1993 in Germany, in which it was estimated that there were more than 1,000 cases of salmonellosis [9]. A variety of Salmonella serotypes were identified during the outbreak and Salmonella Saintpaul, Javiana and Rubislaw were isolated from paprika and paprikapowdered potato chips and from patients. Trace-back investigations and product testing identified paprika, used in seasoning for potato chips, as the contaminated food vehicle.

A more recent outbreak associated with spices occurred in the United Kingdom in 2013. A total of 413 cases of gastroenteritis were associated with a street market spice festival [10]. Uncooked curry leaves that were contaminated with Salmonella Agona PT40 were the source of infection. Additional serotypes, as well as other species of Enterobacteriaceae, were isolated from patients; however, S. Agona PT40 was predominant.

\section{Ongoing assessments and conclusion}

As at 24 July, the outbreak in Sweden currently includes 174 cases, reported from 17 of the 21 counties in Sweden. No other EU countries have confirmed outbreaks or an increase in the number of cases with the outbreak strain. In countries with a high number of reported cases of $S$. Enteritidis infection, however, a small increase in number of cases with the outbreak strain could go undetected. The detection of Salmonella spp. in two different brands of spice mixes sold in Sweden and the RASFF alert from Austria during the outbreak period, however, indicates that there could be a common ingredient in these mixes that could be contaminated with Salmonella spp. Thus, there is a risk that contaminated products are also on the market in other countries.

Information and updates about the outbreak have been posted on the websites of the Public Health Agency of Sweden and the National Food Agency. Press releases from local investigators as well as from the national authorities have also been issued. The outbreak received a lot of media attention in connection with the increasing number of cases connected to the restaurant in Kalmar county, which has been closed due to the outbreak. The national outbreak is still ongoing and more spice mixes are being analysed. This outbreak highlights the complexity of a stealth food vehicle ('stealth foods are those that people may eat but are unlikely to remember' [12]) with a long shelf life.

\section{Acknowledgements}

We would like to acknowledge all the members of the Outbreak Control Team: county medical offices, clinical microbiological laboratories, municipality environmental and health authorities, the Swedish Veterinary Institute and the National Food Agency for their valuable work in the investigation. We would especially like to thank the local authorities in the county of Kalmar.

We would also like to thank Anneli Rasmusson, Eva Borg and Kristina Schönmeyr for excellent laboratory technical assistance and Erik Alm for the bioinformatics analysis, all at the Public Health Agency of Sweden. For the work comparing the Swedish sequences from whole genome sequencing at Public Health England (PHE), we gratefully thank Tim Dallman.

\section{Conflict of interest}

None declared.

Authors' contributions

Cecilia Jernberg drafted the manuscript, was part of the outbreak investigation team and responsible for the international communications and data sharing. Emma Löf was responsible for the epidemiological data collection during the study period and coordination of the local authorities, and critically reviewed the manuscript. Marika Hjertqvist was responsible for epidemiological coordination in the Kalmar outbreak. Anna Pääjärvi was responsible for the microbiological analysis during the study period and Camilla Sundborger for the microbiological analysis during the Kalmar outbreak. Elsie Castro, Margareta Löfdahl, Lena Sundqvist were part of the outbreak investigation team. All authors read and approved the manuscript.

\section{References}

1. Public Health Agency of Sweden. Salmonellainfektion. [Samonella infection]. Solna: Public Health Agency of Sweden. [Accessed 10 Jul 2015]. Swedish. Salmonella statistics available from: http://www.folkhalsomyndigheten. se/amnesomraden/statistik-och-undersokningar/ sjukdomsstatistik/salmonellainfektion/?t=com

2. Ward LR, de Sa JDH, Rowe B. A phage-typing scheme for Salmonella enteritidis. Epidemiol Infect. 1987;99(2):291-4. http://dx.doi.org/10.1017/S0950268800067765 PMID:3315705

3. Hopkins KL, Peters TM, de Pinna E, Wain J. Standardisation of multilocus variable-number tandem-repeat analysis (MLVA) for subtyping of Salmonella enterica serovar Enteritidis. Euro Surveill. 2011;16(32). PMID:21871223

4. European Centre for Disease Prevention and Control (ECDC) EPIS (Epidemic Intelligence Information System). Stockholm: ECDC. [Accessed 23 Jul 2015]. Available from: http://ecdc. europa.eu/EN/ACTIVITIES/EPIDEMICINTELLIGENCE/Pages/ EpidemicIntelligence Tools.aspx

5. European Commission (EC). RASFF - food and feed safety alerts. Brussels/Luxembourg: EC. [Accessed 10 Jul 2015]. Available from: http://ec.europa.eu/food/food/rapidalert/ index_en.htm

6. European Centre for Disease Prevention and Control (ECDC). The European Surveillance System (TESSy). Stockholm: ECDC. [Accessed 23 Jul 2015]. Available from: http://ecdc.europa.eu/ en/activities/surveillance/tessy/pages/tessy.aspx

7. International Organization for Standardization (ISO). ISO 6579:2002. Microbiology of food and animal feeding stuffs - Horizontal method for the detection of Salmonella spp. Geneva: ISO. [Accessed 24 Jul 2015]. Available from: http:// www.iso.org/iso/home/store/catalogue ics/catalogue detail ics.htm?csnumber $=\mathbf{2 9 3 1 5}$

8. United States Food and Drug Administration (FDA). Draft risk profile: pathogens and filth in spices. Silver Spring, MD: FDA; 2013. Available from: http://www.fda.gov/downloads/Food/ FoodScienceResearch/RiskSafetyAssessment/UCM367337.pdf

9. Lehmacher A, Bockemühl I, Aleksic S. Nationwide outbreak of human salmonellosis in Germany due to contaminated paprika and paprika-powdered potato chips. Epidemiol Infect. 1995;115(3):501-11. http://dx.doi.org/10.1017/ So950268800058660 PMID:8557082 
10. Public Health England (PHE). Outbreak of Salmonella Agona phage type 40 associated with the Street Spice Festival,

Newcastle upon Tyne. February / March 2013. Outbreak report.

ILOG 8168. Newcastle upon Tyne: PHE; Jun 2013. Available

from: http://www.newcastle.gov.uk/sites/drupalncc.newcastle.

gov.uk/files/wwwfileroot/environment/environmental

health/20130617_street_spice_oct_report_-_final.pdf

11. Zweifel C, Stephan R. Spices and herbs as source of

Salmonella-related foodborne diseases. Food Res

Int. 2012;45(2):765-9. http://dx.doi.org/10.1016/j.

foodres.2011.02.024

12. Centers for Disease Control and Prevention (CDC). Foodborne diseases epidemiology at a glance. Atlanta, GA: CDC.

[Accessed $24 \mathrm{Jul} 2015]$. Available from: http://www.cdc.gov/ ncezid/dfwed/PDFs/epi101-508c.pdf 